\title{
Distância genética e sua associação com heterose e desempenho de híbridos em aveia
}

\author{
Claudir Lorencetti(1), Fernando Irajá Félix de Carvalho(2), Antonio Costa de Oliveira(2), \\ Igor Pirez Valério ${ }^{(2)}$, Giovani Benin ${ }^{(3)}$, Paulo Dejalma Zimmer ${ }^{(2)}$ e Eduardo Alano Vieira(4)
}

\begin{abstract}
(1)Alliance One, Rua Thomas Gonzaga, no 666, CEP 96880-000 Vera Cruz, RS. E-mail: clorencetti@aointl.com (2)Universidade Federal de Pelotas, Fac. de Agronomia Eliseu Maciel, Dep. de Fitotecnia, Campus Universitário, s/no, CEP 96010-900 Pelotas, RS. E-mail: carvalho@ufpel.tche.br, acostol@terra.com.br, igorvalerio@hotmail.com, dejalma@msn.com (3)Universidade Tecnológica Federal do Paraná, Curso de Agronomia, Rod. PR 469, Km 1, CEP 85501-970 Pato Branco, PR. E-mail: benin@pb.cefetpr.br ${ }^{(4)}$ Embrapa Cerrados, BR 020, Km 18, Caixa Postal 08223, CEP 73310-970 Planaltina, DF. E-mail: vieiraea@cpac.embrapa.br
\end{abstract}

\begin{abstract}
Resumo - O objetivo deste trabalho foi avaliar o efeito da dissimilaridade genética, aferida por caracteres morfológicos e marcadores moleculares, sobre a heterose e heterobeltiose em híbridos de aveia. Foram utilizados cinco genitores cruzados na forma dialélica, tendo sido desconsiderados os híbridos recíprocos. Não houve relação linear entre as medidas de dissimilaridade genética utilizadas, possivelmente em virtude da representação parcial e insuficiente do genoma, quando utilizados dados morfológicos, pela falta de ligação entre os genes controladores dos caracteres mensurados e os marcadores usados, ou pelo fato de as regiões cromossômicas, acessadas pelos marcadores, possuírem diferenças nas suas contribuições para desempenho e heterose da $\mathrm{F}_{1}$. Além disso, as medidas realizadas por meio de caracteres morfológicos e marcadores moleculares não revelam associação significativa com desempenho, heterose e heterobeltiose dos híbridos, para rendimento de grãos.
\end{abstract}

Termos para indexação: Avena sativa, dissimilaridade, aveia-branca, marcadores moleculares.

\section{Genetic distance and its association with heterosis and performance of hybrids on oat}

\begin{abstract}
The objective of this work was to assess genetic dissimilarity effect, as determined by morphological traits and molecular markers, on heterosis and heterobeltiosis in oat hybrids. Five parent lines were crossed in a diallelic design, disregarding reciprocal hybrids. No linear relationship among means of genetic dissimilarity was established, possibly due to: an incomplete genomic description, when morphological data were analyzed; absence of linkage among genes controlling the measured characters and markers employed; or the fact that the different chromosome regions, accessed by the markers, showed differences in their contributions to performance and heterosis of $F_{1}$. Furthermore, regarding grain yield, both measurements determined by morphological traits and molecular markers do not show significant relationship with hybrids performance, heterosis or heterobeltiosis.
\end{abstract}

Index terms: Avena sativa, dissimilarity, white oats, molecular markers.

\section{Introdução}

As informações sobre a dissimilaridade genética assumem grande importância, por possibilitar a previsão do desempenho de híbridos empregados comercialmente (Kumar, 1999). Os vários passos envolvidos no desenvolvimento de híbridos, como a realização de numerosos cruzamentos e a seleção de combinações com desempenho superior, podem ser facilitados, reduzindo o trabalho e os custos associados. Segundo Galanopoulou-Sendouca \& Roupakias (1999), nas culturas em que as sementes híbridas não podem ser utilizadas diretamente, a heterose na geração $F_{1}$ é importante, quando o rendimento da $\mathrm{F}_{1}$ revelar correlação com rendimentos de bulks de gerações mais avançadas. Com isso, os melhoristas podem avaliar um determinado número de híbridos $\mathrm{F}_{1}$ e concentrar seus esforços naqueles mais promissores, dos quais podem ser selecionadas constituições genéticas superiores. Kumar (1999) afirma que a heterose pode ser estimada antes da realização dos cruzamentos, o que reduz consideravelmente o número de cruzamentos a serem executados e as progênies a serem avaliadas.

Vários trabalhos foram conduzidos no sentido de se averiguarem relações de dissimilaridade genética entre os genitores com heterose na geração $\mathrm{F}_{1}$. De acordo com Schut et al. (1997), diferentes caracteres de plantas são fontes de informação de dissimilaridade que es- 
tão, ou podem estar, disponíveis para qualquer grupo de genótipos. Tais caracteres podem ser divididos em quatro grupos: agronômicos, morfológicos, bioquímicos (por exemplo, isoenzimas) e marcadores moleculares (DNA). As diferenças entre genótipos, em relação a quaisquer destes caracteres, revelam informações sobre as relações genéticas entre as constituições estudadas.

Duas medidas de dissimilaridade genética têm sido amplamente utilizadas, quando existem dados agronômicos ou morfológicos: a distância euclidiana entre os pontos que representam os genótipos em um plano e a distância generalizada de Mahalanobis - extensão da distância euclidiana, que leva em consideração as correlações residuais entre os caracteres. No caso de isoenzimas e marcadores moleculares, em que há disponibilidade de dados binários, uma medida de dissimilaridade comumente empregada é a de Nei \& Li (Schut et al., 1997).

A heterose em aveia pode estar positivamente associada à distância genética baseada em caracteres morfológicos dos genitores (Jenkins, 1969). Em estudos com esta planta, Cowen (1985) encontrou correlações baixas e negativas entre duas medidas de dissimilaridade genética, com heterose para rendimento de grãos. Além disso, o mesmo autor relatou que, em cruzamentos entre genitores mais relacionados, ocorre uma tendência de expressar heterose para rendimento de grãos.

Com o desenvolvimento das técnicas de marcadores moleculares, o polimorfismo de DNA pode ser empregado para acessar a dissimilaridade genética. Vários trabalhos têm buscado correlacionar a dissimilaridade genética, quantificada por marcadores de DNA, com o desempenho dos híbridos; contudo, os resultados revelam discrepâncias (Kumar, 1999). Smith et al. (1990) observaram, em milho, relação entre distância genética dos genitores e desempenho da $\mathrm{F}_{1}$, quando o tamanho da amostra e o número de marcadores usados para análise foram simultaneamente ampliados. Stuber et al. (1992) encontraram, também em milho, relação significativa entre heterozigosidade dos genitores e rendimento dos híbridos, quando o número de linhas genitoras endogâmicas era aumentado. Em estudos de Lanza et al. (1997), o rendimento de grãos de milho evidenciou correlação com distâncias genéticas baseadas em marcadores RAPD. Barbosa-Neto et al. (1996) não conseguiram estabelecer qualquer relação entre distância genética baseada em marcadores e o desempenho dos híbridos de trigo.
O objetivo deste trabalho foi avaliar o efeito da dissimilaridade genética, aferida por caracteres morfológicos e marcadores moleculares, sobre a heterose e heterobeltiose em híbridos de aveia.

\section{Material e Métodos}

O experimento foi instalado na área experimental do Centro de Genômica e Fitomelhoramento da Universidade Federal de Pelotas, no Município de Capão do Leão, RS, em 2002. A adubação e o controle fitossanitário foram realizados de acordo com as recomendações para a cultura (Comissão Brasileira de Pesquisa de Aveia, 2003).

Cinco genótipos de aveia foram cruzados de forma dialélica, sem a realização dos cruzamentos recíprocos. Os genitores foram escolhidos com base no rendimento de grãos, nos caracteres agronômicos de interesse e na divergência morfológica apresentada. Os cinco genótipos, seguidos do ano de lançamento e suas respectivas genealogias, foram: UPF 16, 1993, Coronado/ X1799-2//Sel11 Passo Fundo///X3530-40; UPF 18, 1999, UPF $85 S 0238$ x UPF 12; UFRGS 7, 1986, X1205 x FLA 1093; UFRGS 17, 1996, Cor2/Ctz3/Pendek/ ME1563//76-29/76-23/75-28/CI833; URPel 95/015; UFRGS 881920 x UFRGS 884021-1. As sementes híbridas foram obtidas durante a estação fria de 2001, em casa de vegetação, por meio de hibridações artificiais.

Os híbridos $\mathrm{F}_{1}$ e os genitores foram cultivados em parcelas, com delineamento completamente casualizado, com três repetições. Cada parcela experimental foi composta de dez plantas, cultivadas em uma linha de $3 \mathrm{~m}$ de comprimento, com espaçamento de 0,3 m entre plantas e entre linhas. Foram avaliados, em plantas individuais e na panícula principal, os caracteres: ciclo vegetativo, em dias, da emergência até a exposição total da panícula principal; estatura de plantas, em centímetros, da superfície do solo até a extremidade superior da panícula; ciclo reprodutivo, em dias, do florescimento até a maturação de colheita; número de panículas por planta; número de grãos por panícula; e massa de panícula, de grãos por panícula, de 1.000 grãos e de grãos por parcela, em gramas, com base em todas as panículas da planta. As demais panículas da planta foram trilhadas, fornecendo a estimativa do rendimento de grãos (RG). Os dados foram utilizados para estimar a heterose, a heterobeltiose e a dissimilaridade genética baseada em dados morfológicos. 
A heterose foi obtida em relação à média dos genitores: $\mathrm{H}_{\mathrm{mp}}=\frac{\overline{\mathrm{F}}_{1}-\overline{\mathrm{MG}}}{\overline{\mathrm{MG}}} 100$

e ao genitor superior, denominada de heterobeltiose: $\mathrm{H}_{\mathrm{ps}}=\frac{\overline{\mathrm{F}_{1}}-\overline{\mathrm{GS}}}{\overline{\mathrm{GS}}} 100$,

em que: $H_{m p}$ é a estimativa da heterose, em relação à média dos genitores; $\overline{\mathrm{F}}_{1}$ é a média do híbrido; $\overline{\mathrm{MG}}$ é a média dos genitores; $\mathrm{H}_{\mathrm{ps}}$ é a estimativa da heterobeltiose; e $\overline{\mathrm{GS}}$ é a média do genitor superior.

A dissimilaridade genética, entre os genitores, foi estimada pelo uso da distância generalizada de Mahalanobis $\left(\mathrm{D}^{2}\right)$, a partir das médias dos genótipos e da matriz de covariância residual, de acordo com Cruz \& Regazzi (1997). No agrupamento dos genótipos, foi empregado o método hierárquico do vizinho mais próximo, para a formação do dendrograma, com auxílio do programa computacional Genes (Cruz, 2001). Para a verificação do ajuste, entre a matriz de similaridade e o dendrograma obtido, foi calculado o coeficiente de correlação cofenética (r) (Sokal \& Rohlf, 1962), com auxílio do programa computacional NTSYS (Rohlf, 1989).

O DNA genômico utilizado na quantificação da similaridade genética, entre os cinco genótipos, com base em marcadores moleculares, foi extraído de acordo com Saghai-Maroof et al. (1984). Os reagentes e procedimentos, requeridos para a técnica de AFLP (polimorfismo de comprimentos de fragmentos amplificados), foram obtidos da Life Technologies Inc. Foram empregadas cinco combinações de oligonucleotídeos iniciadores $\left(\mathrm{C}_{1}\right.$ : E-ACC/M-CAA; $\mathrm{C}_{2}:$ E-ACC/M-CAG; $\mathrm{C}_{3}: E-\mathrm{ACC} /$ $M-C T C ; \mathrm{C}_{4}$ : E-AGC/M-CAA; $\mathrm{C}_{5}$ : E-AGC/M-CTC; em que $C_{i}$ é a i-ésima combinação de iniciadores; E: EcoRI e M: MseI).

Os fragmentos amplificados foram separados, eletroforeticamente, em gel desnaturante de poliacrilamida (6\%), à potência constante de $60 \mathrm{~W}$, por uma hora e 40 minutos. Para a visualização dos fragmentos amplificados e separados eletroforeticamente, foi empregada a coloração com nitrato de prata, de acordo com Creste et al. (2001).

As bandas geradas pela técnica de AFLP foram classificadas como presente (1) e ausente (0), para os diferentes genitores. A similaridade genética (SG) foi estimada de acordo com Nei \& Li (1979):

$\mathrm{Sg}_{\mathrm{ij}}=2 \mathrm{~N}_{\mathrm{ij}} /\left(\mathrm{N}_{\mathrm{i}}+\mathrm{N}_{\mathrm{j}}\right)$,

em que: $\mathrm{N}_{\mathrm{ij}}$ é o número de bandas presentes em ambos os genótipos i e j; $\mathrm{N}_{\mathrm{i}}$ é o número de bandas presentes no genótipo i; e $\mathrm{N}_{\mathrm{j}}$ é o número de bandas presentes no genótipo j. Subtraído o valor de SG da unidade (1 - SG), foi obtida a dissimilaridade genética e, com base nesta matriz, foi construído um dendrograma, pelo método de agrupamento UPGMA. Além do coeficiente de correlação cofenética, o teste de Mantel (Mantel, 1967), que compara duas matrizes de distâncias genéticas $\left(\mathrm{r}_{\mathrm{m}}\right)$, foi realizado com auxílio do programa computacional NTSYS (Rohlf, 1989).

A estabilidade estatística das estimativas de dissimilaridade genética pode ser influenciada pela amostragem (Efron \& Tibshirani, 1993). Assim, a estabilidade dos agrupamentos foi cancelada pela análise de bootstrap (teste da consistência dos agrupamentos, por meio de diversas repetições), com 500 replicações, utilizando-se o programa computacional Winboot (Yap \& Nelson, 1996).

O coeficiente de correlação de Pearson entre dissimilaridade genética, heterose, heterobeltiose e desempenho dos híbridos, para os diferentes caracteres, com significância testada pelo teste t, foi estimado com utilização do programa computacional Genes (Cruz, 2001).

\section{Resultados e Discussão}

As médias e amplitudes de variação para desempenho, heterose e heterobeltiose estão incluídas na Tabela 1. O grau de heterose variou entre os caracteres avaliados. A maior heterose média foi revelada na massa de

Tabela 1. Médias e amplitude de variação do desempenho, heterose e heterobeltiose, dos principais caracteres de importância agronômica dos híbridos $\mathrm{F}_{1}$, resultantes do cruzamento dialélico parcial entre cinco genitores, em aveia ${ }^{(1)}$.

\begin{tabular}{|c|c|c|c|c|c|c|}
\hline \multirow[t]{2}{*}{ Caráter } & \multicolumn{2}{|c|}{ Desempenho } & \multicolumn{2}{|c|}{ Heterose $(\%)$} & \multicolumn{2}{|c|}{ Heterobeltiose (\%) } \\
\hline & Média & Amplitude & Média & Amplitude & Média & Amplitude \\
\hline EST & 99,1 & $82,0-112,0$ & 6,1 & $-2,1-16,8$ & 12,8 & $-1,9-29,4$ \\
\hline $\mathrm{CV}$ & 99,3 & $96,0-101,0$ & $-2,1$ & $-5,2-(-) 0,6$ & 1,2 & $-1,5-6,4$ \\
\hline $\mathrm{CR}$ & 38,1 & $34,0-43,0$ & 4,5 & $-1,8-14,3$ & $-0,9$ & $-8,5-13,6$ \\
\hline NPP & 7,0 & $5,0-9,0$ & $-5,3$ & $-21,4-21,6$ & $-22,6$ & $-36,3-(-) 7,2$ \\
\hline PP & 5,5 & $4,6-7,4$ & 55,4 & $28,8-89,7$ & 30,8 & $5,8-67,5$ \\
\hline NGP & 136,2 & $112,0-178,0$ & 33,9 & $8,4-75,9$ & 19,3 & $4,1-40,3$ \\
\hline PGP & 4,7 & $3,9-6,5$ & 55,5 & $33,5-105,3$ & 35,2 & $1,7-79,3$ \\
\hline PMG & 35,1 & $29,0-40,0$ & 15,1 & $4,1-28,7$ & 4,8 & $-8,4-20,3$ \\
\hline RG & 190,3 & $135,0-330,0$ & 53,0 & $11,9-153,1$ & 25,4 & $-13,2-56,4$ \\
\hline
\end{tabular}

(1)EST: estatura de plantas, em cm; CV: ciclo vegetativo, em dias; CR: ciclo reprodutivo, em dias; NPP: número de panículas por planta; PP: massa de panícula, em g; NGP: número de grãos por panícula; PGP: massa de grãos por panícula, em g; PMG: massa de 1.000 grãos, em g; e RG: rendimento de grãos da parcela, em g. 
grãos por panícula (PGP, 55,5\%), seguida pela massa de panícula (PP, 55,4\%) e rendimento de grãos (RG, 53\%). Resultados semelhantes foram observados em experimentos realizados em três locais e composto de oito cruzamentos, em que a heterose para RG variou de 19,5 a 50,6\% (Cowen \& Frey, 1987), e concordam com aqueles obtidos por Petr \& Frey (1967), em que a heterose para RG em 15 cruzamentos, avaliada em planta espaçada, variou de 18 a 56\%.

Os valores elevados de heterose para RG são ocasionados, principalmente, pelos efeitos gênicos não aditivos, como revelado na análise dialélica, em que foram de maior magnitude, comparados aos efeitos aditivos dos genes. Este fato pode revelar dificuldades para seleção de plantas nas gerações segregantes precoces, uma vez que os efeitos não aditivos podem ser perdidos durante o processo de condução à homozigose. Entretanto, Cruz \& Regazzi (1997) afirmam que, em espécies autógamas, combinações que expressam elevada heterose em $\mathrm{F}_{1}$ oferecem maior probabilidade de resgate de indivíduos superiores nas gerações segregantes.

Para heterobeltiose, os maiores valores também foram evidenciados pelos mesmos caracteres (Tabela 1). Foi observada heterose negativa para número de panículas por planta (NPP) e ciclo vegetativo (CV), enquanto os valores de heterobeltiose foram negativos para NPP e ciclo reprodutivo (CR). A heterose para $\mathrm{CV}$ foi negativa em todos os cruzamentos, tendo variado de -5,2 a -0,6\%; entretanto, quando o CV foi comparado ao melhor genitor (heterobeltiose), mostrou que, para pelo menos um cruzamento, foi mais elevado que o do genitor mais precoce. $\mathrm{O} \mathrm{CV}$, seguido pelo $\mathrm{CR}$, exibiu baixa heterose e pequena amplitude de variação de heterose, o que indica que os genes que controlam estes dois caracteres são similares nos diferentes genótipos,

A)

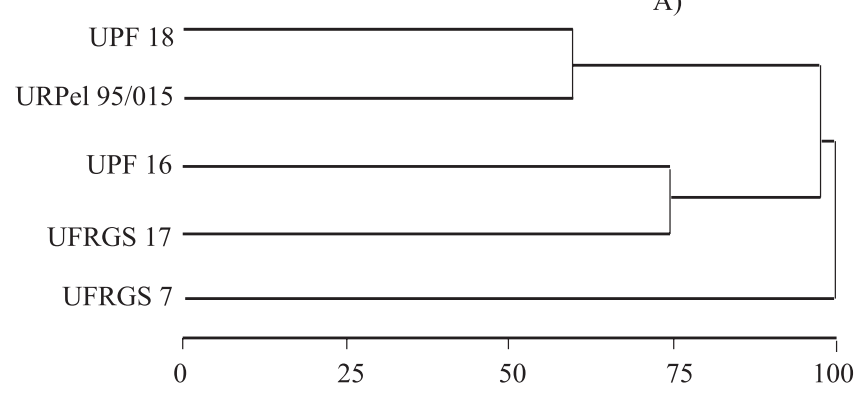

e não ocorre distribuição de alelos dominantes entre eles, conforme sugerem Morgan et al. (1989).

Na análise molecular, a utilização de cinco combinações de oligonucleotídeos iniciadores gerou um total de 250 bandas, das quais $189(75,6 \%)$ revelaram polimorfismo, pela técnica de AFLP. As combinações $\mathrm{C}_{3}, \mathrm{C}_{4} \mathrm{e} \mathrm{C}_{1}$ evidenciaram o maior número de marcadores polimórficos, 54, 52 e 43, respectivamente. Por outro lado, $\mathrm{C}_{4}, \mathrm{C}_{1}$ e $\mathrm{C}_{3}$ evidenciaram a maior quantidade de bandas monomórficas, 18, 17 e 16, respectivamente. Isto demonstra que 78,8\% dos marcadores polimórficos foram gerados por apenas três combinações de iniciadores $\left(C_{3}, C_{4}\right.$ e $\left.C_{1}\right)$, o que evidencia o potencial dos marcadores AFLP em acessar a variabilidade genética existente entre os genótipos estudados.

A dissimilaridade genética entre os genitores foi estimada com dados morfológicos e marcadores moleculares. Na primeira, foram empregados os nove caracteres mencionados anteriormente. Na segunda, a dissimilaridade genética entre os genitores foi estimada com o uso de 189 bandas polimórficas. As matrizes de dissimilaridade genética foram empregadas para a formação dos dendrogramas. A análise de agrupamento baseada na dissimilaridade genética morfológica mostrou comportamento diferenciado daquela baseada em marcadores moleculares (Figura 1). A correlação cofenética foi de 0,77 e 0,76 para dissimilaridade genética (dg) e dissimilaridade morfológica (dm), respectivamente. Assim, os dendrogramas possibilitaram ilustrar graficamente 77 e $76 \%$ das matrizes de dg e dm, respectivamente, evidenciando que as inferências podem ser feitas com base neles. Conseqüentemente, as matrizes de dissimilaridade foram omitidas.

A Figura 1 A revela que os genótipos estão reunidos em dois grupos. O principal constituído por UPF 18,

B)

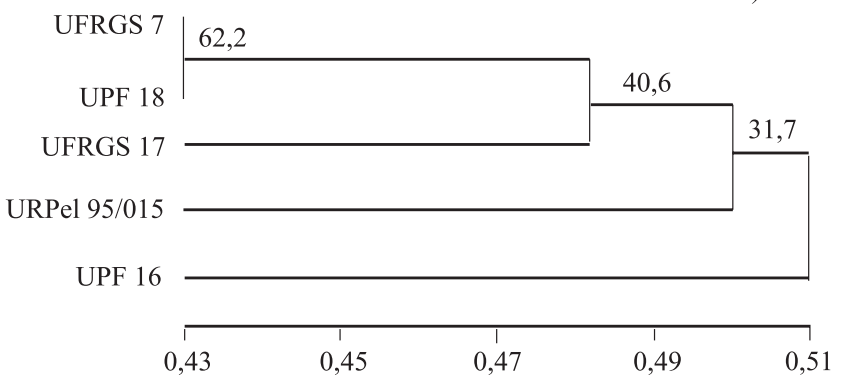

Figura 1. Dendrogramas da análise de agrupamento de cinco genótipos de aveia, obtidos pelo método hierárquico do vizinho mais próximo, utilizando-se a distância de Mahalanobis com base em dados morfológicos, com nove caracteres (A), e pelo método UPGMA com base em dados moleculares de 189 bandas AFLP (B). 
URPel 95/015, UPF 16 e UFRGS 17, que pode ser subdivido em dois subgrupos formados por UPF $18+$ URPel 95/015 e UPF 16 + UFRGS 17. O segundo grupo foi formado apenas por UFRGS 7. A Figura $1 \mathrm{~B}$ mostra que os genótipos mais próximos geneticamente foram UFRGS 7 e UPF 18, evidenciando uma grande discrepância quando comparado com dm, uma vez que na Figura $1 \mathrm{~A}$ eles foram os mais dissimilares. A ausência de concordância das distâncias genéticas entre os genitores, apresentada pelos dendrogramas, foi confirmada pela ausência de correlação $\left(r_{m}=-0,12\right)$ entre as duas matrizes de dissimilaridade. Esses resultados concordam com os obtidos em cevada, em que Schut et al. (1997) mostraram que a dissimilaridade genética, baseada em caracteres morfológicos, não revelou relação com a dissimilaridade genética baseada em marcadores AFLP.

As distorções podem ser decorrentes dos seguintes fatores: limitado número de caracteres morfológicos avaliados; pequena variação entre esses caracteres; limitado número de genes responsáveis pela manifestação desses caracteres; e a possibilidade de efeitos epistáticos entre esses genes. Provavelmente, os dois primeiros fatores são mais importantes para este conjunto de dados, uma vez que apenas nove caracteres morfológicos foram utilizados na análise de dissimilaridade. Resultados semelhantes foram obtidos por Souza \& Sorrells (1991) em aveia, em que os autores levantam a hipótese de que essa baixa correlação se justificaria pela parcial e insuficiente representação do genoma, quando são utilizados dados morfológicos. Como todos os genótipos testados neste trabalho são genótipos elites, cuja seleção nos diferentes programas de melhoramento buscou genótipos precoces, de baixa estatura e mais produtivos, possivelmente tiveram a variabilidade genética reduzida entre os genitores.

Pela análise de bootstrap, apenas o grupo formado pelas cultivares UFRGS 7 e UFP 18 apresentou elevada consistência (62,2\%) (Figura 1 B), apontando para o fato de estas cultivares formarem o agrupamento mais consistente.

A Tabela 2 mostra a correlação entre a dm e o desempenho, a heterose e a heterobeltiose dos híbridos. Os coeficientes de correlação da dm com o desempenho dos híbridos e a heterobeltiose não foram significativos. Em relação à heterose, a dm esteve correlacionada com CR, NPP, massa de 1.000 grãos (PMG) e número de grãos por panícula (NGP), sendo que para os três primeiros, a correlação foi negativa, uma indicação de que um aumento na distância genética entre os genitores vem acompanhado de redução da heterose. É importante observar que a dm não revelou associação significativa com o RG.

Para Falconer (1960), a ocorrência de heterose em $\mathrm{F}_{1}$, para um caráter quantitativo, depende da seguinte relação: $H=\sum_{i} d_{i} Y_{i}^{2}$,

em que: $d_{i}$ é o desvio do heterozigoto da média dos genitores homozigotos, relacionado aos efeitos da dominância no i-ésimo loco; e $\mathrm{Y}_{\mathrm{i}}$ é a diferença de freqüência alélica entre duas constituições genéticas no iésimo loco. Assim, Ghaderi et al. (1984) citaram três situações que podem ocorrer na relação entre a dm, baseada em $\mathrm{D}^{2}$, e a heterose: associação positiva, nula e negativa.

Para que a associação positiva, em um conjunto de cruzamentos, possa ocorrer, é necessário: que exista dominância - e que esta aumente em magnitude à medida que os genitores forem mais dissimilares - e que os genitores sejam diferentes na freqüência dos alelos que controlam o caráter, e que esta diferença seja intensificada quando a distância entre os genitores aumentar. Para caracteres quantitativos, nas espécies em que a autofecundação é responsável pela reprodução, os efeitos heteróticos dependem do número de alelos contrastantes e dos efeitos da dominância. Entretanto, para que haja

Tabela 2. Coeficientes de correlação entre desempenho (DES), heterose (HET) e heterobeltiose (HBT) e dissimilaridade genética, medida por meio de caracteres morfológicos e marcadores moleculares, dos híbridos $\mathrm{F}_{1}$, resultantes do cruzamento dialélico parcial entre cinco genitores de aveia ${ }^{(1)}$.

\begin{tabular}{|c|c|c|c|c|c|c|}
\hline \multirow[t]{2}{*}{ Caráter } & \multicolumn{3}{|c|}{ Caracteres morfológicos } & \multicolumn{3}{|c|}{ Marcadores moleculares } \\
\hline & DES & HET & HTB & DES & HET & HTB \\
\hline EST & $-0,20$ & $-0,29$ & $-0,22$ & 0,02 & $-0,64$ & $-0,90 *$ \\
\hline $\mathrm{CV}$ & $-0,01$ & $-0,25$ & $-0,47$ & $-0,27$ & $-0,62$ & $-0,03$ \\
\hline CR & $-0,39$ & $-0,68^{*}$ & $-0,53$ & $0,65^{*}$ & 0,40 & 0,31 \\
\hline NPP & 0,52 & $-0,63^{*}$ & $-0,34$ & 0,15 & 0,24 & 0,27 \\
\hline PP & 0,04 & 0,19 & 0,12 & 0,48 & $0,63^{*}$ & 0,72 \\
\hline NGP & 0,22 & $0,62 *$ & 0,43 & $-0,17$ & 0,23 & 0,18 \\
\hline PGP & 0,09 & 0,35 & 0,25 & 0,53 & $0,65^{*}$ & 0,77 \\
\hline PMG & $-0,24$ & $-0,77^{*}$ & $-0,47$ & $0,86^{*}$ & 0,31 & 0,52 \\
\hline RG & 0,44 & 0,28 & 0,22 & 0,49 & 0,44 & 0,28 \\
\hline
\end{tabular}

(1)EST: estatura de plantas, em cm; CV: ciclo vegetativo, em dias; CR: ciclo reprodutivo, em dias; NPP: número de panículas por planta; PP: massa de panícula, em g; NGP: número de grãos por panícula; PGP: massa de grãos por panícula, em g; PMG: massa de 1.000 grãos, em g; e RG: rendimento de grãos da parcela, em g. *Significativo a 5\% de probabilidade, pelo teste t. 
uma relação linear entre a dm e a heterose, seus componentes, isolados ou em combinação, devem responder linearmente à variação de $\mathrm{D}^{2}$.

A ausência de correlação pode ser atribuída a efeitos aditivos dos caracteres $(\mathrm{d}=0)$ ou à identidade entre os genes que controlam o caráter nos diferentes genitores $\left(\mathrm{Y}^{2}{ }_{\mathrm{i}}=0\right)$, e à expressão da heterose imprevisível e ao acaso, nos cruzamentos. A primeira situação poderia ser esperada para NPP, PMG, NGP e PP, em que, de acordo com a análise dialélica para estes caracteres (Lorencetti, 2004), houve maior contribuição dos efeitos de capacidade geral de combinação, ou seja, grande participação dos efeitos gênicos aditivos. Entretanto, uma análise dos efeitos heteróticos, em cruzamentos individuais, mostrou que a última situação prevaleceu nesses dados, evidenciando que a heterose pode ter resultado da presença de genes complementares entre determinados genitores. Ainda de acordo com Ghaderi et al. (1984), os efeitos negativos e positivos da dominância, num sistema bidirecional, podem resultar em valor nulo $(\mathrm{d}=0)$ dos efeitos heteróticos em certos cruzamentos.

Heteroses para CR, NPP e PMG mostraram correlação negativa com a dm. Em quase todos os cruzamentos, os efeitos heteróticos (amplitude) e CV e NPP foram negativos, evidenciando a hipótese de dominância de genes que favorecem a precocidade e o menor número de afilhos férteis por planta (d negativa).

É importante observar que a associação não significativa da dm com a heterose, para o RG, pode ser questionada de um ponto de vista compensatório entre componentes de rendimento; ou seja, a associação negativa da heterose para NPP $(-0,63)$ e PMG $(-0,77)$ e positiva para NGP $(0,62)$ com a dm parece conduzir a um efeito compensatório entre os componentes do rendimento, o que pode ter resultado na ausência de correlação entre a dm e a heterose para o RG.

A Tabela 2 mostra a correlação da dg com o desempenho, a heterose e a heterobeltiose da $\mathrm{F}_{1}$. Os resultados revelam que a dg esteve associada, positivamente, com o desempenho de CR e PMG, com a heterose e a heterobeltiose de PP e NGP, e negativamente associada com a heterose de estatura de plantas (EST) e de CV e com a heterobeltiose de EST. Para o RG, apesar de uma estimativa moderada de correlação entre a heterose e a dg $(0,49)$, não foi detectada significância, sendo semelhante ao valor da correlação encontrado para a dm e a heterose para o RG $(0,44)$. Os dados ainda revelaram ausência de concordância entre as correlações baseadas na dm e na dg (Tabela 2) com o de- sempenho dos híbridos, a heterose e a heterobeltiose. Neste caso, o acréscimo da dg não foi seguido linearmente pela elevação dos valores da heterose.

Kwon et al. (2002), em estudos com arroz, sugerem que a baixa correlação entre a dg e o desempenho da $F_{1}$ pode ocorrer em virtude de: os genótipos avaliados apresentarem baixa dissimilaridade genética, pela pressão de seleção exercida no mesmo sentido que para ciclo curto, estatura baixa, maior massa de 1.000 grãos e maior massa de panícula; falta de ligação entre genes que controlam os caracteres mensurados e os marcadores usados para estimar a dg; as regiões cromossômicas acessadas pelos marcadores terem diferenças nas suas contribuições para o desempenho e a heterose da $F_{1}$. Neste estudo, houve dificuldades de predição do desempenho e da heterose da $F_{1}$ a partir da dg, no conjunto de genitores testados. Este fato é relevante, principalmente se a heterose dos híbridos desses genitores estiver associada com desempenho médio de bulks de gerações avançadas - neste caso, há uma indicação de ineficiência do uso da dissimilaridade na escolha dos genitores para compor os blocos de cruzamentos, revelando a necessidade da realização de cruzamentos dialélicos para esta finalidade, em aveia.

O número de genótipos utilizados foi baixo, resultando em apenas dez combinações híbridas. Dessa forma, os valores dos coeficientes de correlação, para evidenciar significância, devem ser elevados, uma vez que o número de graus de liberdade é reduzido, indicando a necessidade de se testarem mais genótipos em combinações híbridas, para confirmar tais resultados.

Zhang et al. (1994) trabalharam com oito linhas elites de arroz, para determinar as relações entre a heterozigosidade, o desempenho e a heterose. Esses estudos revelaram que a correlação entre a heterose e a heterozigosidade específica (baseada em marcadores positivos, ou seja, significativamente associada com o caráter) foi elevada e que pode ser útil para a predição da heterose.

Assim, vários autores, ao trabalhar com diferentes culturas, sugerem que marcadores positivos, em lugar de marcadores que acessam o genoma e não mostram associação significante com o caráter, podem ser úteis para predizer os resultados (Moser et al., 1994). Os dados destes experimentos conduzem aos mesmos resultados, e mostram que os marcadores utilizados (em acesso aleatório ao genoma) podem não apresentar utilidade aos programas de melhoramento, na predição do desempenho e da heterose, em cruzamentos de aveia. 


\section{Conclusões}

1. As medidas de dissimilaridade genética em aveia, realizadas por meio de caracteres morfológicos e marcadores moleculares, não se correlacionam.

2. As medidas de dissimilaridade genética, para rendimento de grãos, não revelam associação com a heterose e a heterobeltiose dos híbridos.

\section{Agradecimentos}

À Fapergs, ao CNPq e à Capes, pelos auxílios recebidos e pelas bolsas de pós-graduação, iniciação científica e produtividade em pesquisa.

\section{Referências}

BARBOSA-NETO, J.F.; SORRELLS, M.E.; CISAR, G. Prediction of heterosis in wheat using coefficient of parentage and RFLP-based estimates of genetic relationship. Genome, v.39, p.1142-1149, 1996.

COMISSÃO BRASILEIRA DE PESQUISA DE AVEIA. Indicações técnicas para a cultura da aveia (grãos e forrageira). Passo Fundo: UPF: UFRGS, 2003. 86p.

COWEN, N.M. Relationships between three measures of genetic distance and heterosis, transgressive segregation and generalized genetic variances in oats. In: COWEN, N.M. Genetic diversity of Midwestern oat germplasm: part II. 1985. p.81-101. Thesis (Ph.D.) - Iowa State University, Ames, Iowa.

COWEN, N.M.; FREY, K.J. Relationships between three measures of genetic distance and breeding behavior in oats (Avena sativa L.). Genome, v.29, p.97-106, 1987.

CRESTE, S.; TULMANN-NETO, A.; FIGUEIRA, A. Detection of single sequence repeat polymorphisms in denaturing polyacrylamide sequencing gels by silver staining. Plant Molecular Biology Reporter, v.19, p.299-306, 2001.

CRUZ, C.D. Programa Genes: aplicativo computacional em genética e estatística. Viçosa: UFV, 2001. 648p.

CRUZ, C.D.; REGAZZI, A.J. Modelos biométricos aplicados ao melhoramento genético. Viçosa: UFV, 1997. 390p.

EFRON, B.; TIBSHIRANI, R.J. An introduction to the bootstrap. New York: Chapman \& Hall, 1993. 436p.

FALCONER, D.S. Introduction to quantitative genetics. New York: Ronald Press Co., 1960. 365p.

GALANOPOULOU-SENDOUCA, S.; ROUPAKIAS, D. Performance of cotton $\mathrm{F}_{1}$ hybrids and its relation to the mean yield of advanced bulk generations. European Journal of Agronomy, v.11, p.53-62, 1999.

GHADERI, A.; ADAMS, M.W.; NASSIB, A.M. Relationship between genetic distance and heterosis for yield and morphological traits in dry edible bean and faba bean. Crop Science, v.24, p.37-42, 1984.
JENKINS, G. Heterosis and combining ability in hybrids of Avena sativa L. and A. byzantina C. Koch. Journal of Agricultural Science, v.72, p.85-92, 1969.

KUMAR, L.S. DNA markers in plant improvement: an overview. Biotechnology Advances, v.17, p.143-182, 1999.

KWON, S.-J.; HA, W.-G.; HWANG, H.-G.; YANG, S.-J.; CHOI, H.-C.; MOON, H.-P.; AHN, S.-N. Relationship between heterosis and genetic divergence in Tongil-type rice. Plant Breeding, v.121, p.487-492, 2002.

LANZA, L.L.B.; SOUZA JUNIOR, C.L. de; OTTOBONI, L.M.M.; VIEIRA, M.L.C.; SOUZA, A.P. de. Genetic distance of inbred lines and prediction of maize single-cross performance using RAPD markers. Theoretical and Applied Genetics, v.94, p.1023-1030, 1997.

LORENCETTI, C. Capacidade combinatória de genitores e suas implicações no desenvolvimento de progênies superiores em aveia (Avena sativa L.). 2004. 102p. Tese (Doutorado) - Universidade Federal de Pelotas, Pelotas.

MANTEL, N. The detection of disease clustering and a generalized regression approach. Cancer Research, v.27, p.209-220, 1967.

MORGAN, C.L.; AUSTIN, R.B.; FORD, M.A.; BINGHAM, J.; ANGUS, W.J.; CHOWDHURY, S. An evaluation of $\mathrm{F}_{1}$ hybrid winter wheat genotypes produced using a chemical hybridizing agent. Journal of Agricultural Science, v.112, p.143-149, 1989.

MOSER, H.; LEE, M. RFLP variation and genealogical distance, multivariate distance, heterosis, and genetic variation in oats. Theoretical and Applied Genetics, v.87, p.947-956, 1994.

NEI, M.; LI, W. H. Mathematical model for studying genetic variation in terms of restriction endonucleases. Proceedings of the National Academy of Sciences of the United States of America, v.76, p.5269 5273, 1979.

PETR, F.C.; FREY, K.J. Heterosis in oats. Crop Science, v.7, p.33 36, 1967.

ROHLF, F.J. NTSYS pc: numerical taxonomy and multivariate analysis system. New York: Exeter Pub. Co., 1989. 38p.

SAGHAI MAROOF, M.A.; SOLIMAN, K.M.; JORGENSEN, R.A.; ALLARD, R.W. Ribosomal DNA spacer-length polymorphisms in barley: Mendelian inheritance, chromosomal location, and population dynamics. Proceedings of the National Academy of Sciences of the United States of America, v.81, p.8014 8018, 1984.

SCHUT, J.W.; QI, X.; STAM, P. Association between relationship measures based on AFLP markers, pedigree data and morphological traits in barley. Theoretical and Applied Genetics, v.95, p.1161 1168, 1997.

SMITH, O.S.; SMITH, J.S.C.; BOWEN, S.L.; TENBORG, R.A.; WALL, S.J. Similarities among a group of elite maize inbreds as measured by pedigree, $\mathrm{F}_{1}$ grain yield, grain yield, heterosis, and RFLPs. Theoretical and Applied Genetics, v.80, p.833 840, 1990.

SOKAL, R.R.; ROHLF, F.J. The comparison of dendrograms by objective methods. Taxonomy, v.11, p.33-40, 1962.

SOUZA, E.; SORRELLS, M.E. Relationships among 70 North American oat germplasms. II. Cluster analysis using qualitative characters. Crop Science, v.31, p.605-612, 1991. 
STUBER C.W.; LINCOLN, S.E.; WOLFF, D.W.; HELENTJARIS, T.; LANDER, E.S. Identification of genetic factors contributing to heterosis in a hybrid from two elite maize inbred lines using molecular markers. Genetics, v.132, p. 823-839, 1992.

YAP, I.V.; NELSON, R.J. Winboot: a program for performing bootstrap analysis of binary data to determine the confidence limits of UPGMA-based dendrograms. Manila: IRRI, 1996. 22p. (IRRI discussion paper series, 14).

ZHANG, Q.; GAO, Y.J.; YANG, S.H.; RAGAB, R.A.; SAGHAIMAROOF, M.A.; LI, Z.B. A diallel analysis of heterosis in elite hybrid rice based on RFLPs and microsatellites. Theoretical and Applied Genetics, v.89, p.185-192, 1994.

Recebido em 2 de março de 2005 e aprovado em 6 de outubro de 2005 